\title{
On Innovative Cultivation Mode of Technical and Skilled Talents in Well-adapted and Trend-following Way
}

\author{
Ye Yinzhong \\ Shanghai Urban Construction Vocational College, Shanghai, China \\ Email address: \\ yzye@succ.edu.cn
}

\section{To cite this article:}

Ye Yinzhong. On Innovative Cultivation Mode of Technical and Skilled Talents in Well-adapted and Trend-following Way. International Journal of Vocational Education and Training Research. Vol. 6, No. 1, 2020, pp. 11-16. doi: 10.11648/j.ijvetr.20200601.12

Received: April 18, 2020; Accepted: May 18, 2020; Published: June 16, 2020

\begin{abstract}
It is the main task of advanced vocational education at present and in the future to keep up with the pulse of the construction of modern vocational education system, improving the level of running schools and the quality of personnel training. Shanghai Urban Construction Vocational College originates from three vocational colleges. With a long-term school running history, the newly established vocational college is at a new starting point of development. There is a long way to go to realize innovation in inheritance and development in integration. For the better development of the school, we must actively adapt to the needs of national and regional economic and social development and the situation and tasks of comprehensive education reform of national and local governments; grasp and make good use of various development opportunities to meet full needs of industries and enterprises; always regard exploring and improving the ability of talent cultivation as our core task; follow the law and path of quality maintenance, continuously innovate on talent training mode, play a good role in social service, enhance their own characteristics in the service, and enhance the comprehensive strength in the service.
\end{abstract}

Keywords: Needs of Economic and Social Development, Technical and Skilled Talents, Integration Between Industry and Education, Talent Cultivation

\section{Introduction}

In order to accelerate the development of modern vocational education system, as the measure of implementing the Comprehensive Reform Plan of Education in Shanghai [1] and Shanghai Higher Education Layout Structure and Development Plan [2], Shanghai Urban Construction Vocational College (hereafter referred to as SUCC) was formed by merging Shanghai Technical College of Urban Management and Shanghai Jianfeng Vocational College in April 2016, while the latter two institutions being featured with programs on architecture, civil engineering and urban management in the field of construction. The following July also witnessed the trusteeship that SUCC took on for the academic education sector of Shanghai Vocational College of Trade Union, which had a long history in the fields like public management and social services and also boasted programs of distinct characteristic. Therefore, SUCC could be regarded as "a new college with long-term experiences" on the basis of the combination of two schools but integrating three colleges' culture.
Veterans are exploring new initiatives. Facing with new targets and tasks, SUCC has taken integration and development as well as inheritance and innovation as its main tasks and adhered to the principle of "Seeking Progress in Stability, Braving for Innovation". It has been devoted to promoting development through in-depth integration and deepening integration along the developing way. SUCC has also been committed to inheriting the schooling foundation and characteristics accumulated from the three predecessors with decades of history, in the hope of "adapting to the needs". Striving to grasp the favorable conditions of comprehensive reform of education and development of modern vocational education, SUCC conforms to the new trend of regional economic and social development, and makes the endeavor to innovate the training mode of technical and skilled talents. With the orientation of cultivating advanced technical, skilled and applied talents adapted to the novel trend of industrial and technological development, and serving the areas of urban construction, management and service, SUCC aims at building a high-level vocational college with distinctive characteristics. Meanwhile SUCC makes efforts to improve 
the level of talents cultivation to fulfill the fundamental task of fostering morality and nurturing talents.

\section{Establishing a Reference System for School Development in a "Well-Adapted" Way}

As the important part of the national education system and human resource development, the vocational education shoulders the responsibilities of developing a diversified pool of talents, passing on technical skills and boosting employment and entrepreneurship. It supplies one of the major paths for the young people to achieve success.

Accelerating the development of modern vocational education is a fundamental basis for realizing sustainable economic and social development. It is significant not only to give full play to the advantages of labor power and brainpower in China, but also to enhance the comprehensive competitiveness of the real economy [3]. In past years, we have seen significant achievements in the reform and development of vocational education throughout China. Shanghai, as a pilot area for the nationwide comprehensive educational reform, is continuously deepening the initiative in the vocational sector. In March 2015, The Decision on Accelerating the Development of Modern Vocational Education [4] was issued by Shanghai Municipal People's Government. In December of the same year, Shanghai Modern Vocational Education System Construction Plan (2015-2030) [5], released jointly by five departments including Shanghai Municipal Education Commission, put forward the target of setting up a modern vocational education system with Chinese characteristics, world level and Shanghai features. The development of vocational education in Shanghai has been speeding up.

In December 2019, the Shanghai Municipal Government has published the Action Plan for High-quality Development of Vocational Education in Shanghai (2019-2022) (hereinafter referred to as the "Action Plan") [6]. With a view to the actual demand for technical and skilled personnel and high-quality workers in the process of building Shanghai into a socialist modernized international metropolis, the Action Plan requires relevant stakeholders to take various approaches to meet the needs for industrial development and ensure the supply of human resources. It also requires that multiple resources including the government, society, industries and enterprises be integrated, and effective and efficient measures be taken to gradually solve tough problems in systems and mechanism in a bid to promote the high-quality development of vocational education in Shanghai.

Establishment of SUCC is a specific measure to carry out the Comprehensive Reform Plan of Education in Shanghai, Higher Education Layout and Development Plan in Shanghai, and Shanghai Modern Vocational Education System Construction Plan, which aims at meeting present and future needs of Shanghai and regional economic and social development for technical, skilled and applied talents in urban construction, management and service fields better, providing more powerful talent and intelligence support for urban construction, management and service industries as well as serving the development of young students through "Supply-side Reform". Therefore, since the founding of SUCC, it has consciously grasped the key point of "adapting to the needs", and views the following factors as the main dimension of its reference system: the national strategy of driving innovation and developing real economy; the construction of modern vocational education system; the cultivation of high-quality talents needed by the industry; the promotion of students' lifelong development. The brand-new reform and development blueprint of SUCC is drawn on the higher starting point.

SUCC has further defined its operation orientation-adhering to the development path with characteristics and high quality. According to the "two-dimensional classification system" of Shanghai colleges and universities, SUCC positions itself as a "comprehensive, technical and skilled" college. By learning from the successful schooling experience of application-oriented undergraduate universities, SUCC is serving the construction of modern vocational education system in Shanghai. With the major orientation in urban construction, urban management and urban service, SUCC is striving to form the operation superiority and characteristic. It extends the omnidirectional and systematic reform of education and teaching with the prime goal of improving education, teaching and talents cultivation.

Seeing "the integration of three colleges" as an opportunity, SUCC focuses on optimizing the program layout. It has formulated a plan for the establishment of secondary schools, setting up seven specialized secondary schools such as the School of Civil and Transportation Engineering. Besides, the structure of the schooling entity is further straightened out by establishing the School of International Studies which features Sino-foreign cooperative programs, the School of Continuing Education which specializes in adult education and training, as well as the Department of General Studies and the Department of Ideological \& Political Education. Echoing Shanghai's demand for talents in civil engineering, engineering management, transportation and logistics, urban operation and maintenance, public management service and related fields concerning future urban development, SUCC has clarified the orientation of each secondary school in the initial stage, which lays the foundation for further development in the long run. Focusing on the objectives of Three-year Plan for Innovation and Development [7], SUCC has completed the first-round optimization of program layout by integrating the original 47 programs under 12 majors into the current 38 programs under 11 majors on the basis of the consensus reached through a number of professional construction forums boasting in-depth analysis of the industrial development, talent demand, as well as school's comparative advantages and deficiencies. It is through this initiative that SUCC further clarifies the ideas and measures for the construction of each program, promoting the 
development of integration, clustering, and chaining with respective characteristics, and thus further optimizing the talent cultivation scheme [8].

Currently SUCC is making greater efforts to reform its education and teaching system in a more comprehensive manner, with the aim of cultivating more competitive skilled technical personnel characterized by the capabilities in solving practical problems in workplaces, innovation and creation, and self-developing, with craftsmanship and a certain international perspective. It exerts the spirit of the national and Shanghai conferences on ideological and political work in universities and colleges, adhering to the fundamental task of "fostering morality, cultivating talents" by adopting the "Three Whole Education" model (whole forces, whole process, whole fields). In this respect, SUCC has designed a pilot scheme for the teaching and educating reform of "Ideological and Political Theories Teaching in All Courses" and set up key ideological and political courses. It is also actively carrying out the "Three Whole Education" model by developing "China series" courses of unique characteristics and comprehensive quality courses. In addition, SUCC fully explores the elements of public basic courses and specialized courses concerning the ideological and political education of college students and the cultivation of comprehensive quality, and applies them into each and every section of the whole talent cultivation process of each program. In 2017, SUCC was approved as the key cultivation college for the "Ideological and Political Theories Teaching in All Courses" education and teaching reform project in Shanghai universities and colleges. Up to now, the reform and implementation of the " $1+1+3+20$ " courses ( 1 ideological and political theory course, 1 "China series" course, 3 comprehensive quality courses, 20 professional courses) in the pilot program has being carefully studied and promoted. SUCC offers the innovation entrepreneurship curriculum and incorporates it into the teaching plan, trying to combine innovation consciousness, enterprising spirit and innovative ability with professional education and career competence cultivation [9].

\section{3. "Following Trends" - Seize New Opportunities for School Development}

SUCC is set up following the general trend of Shanghai's comprehensive education reform, the adjustment of local universities and colleges' layout as well as the development of modern vocational education. Its prosperous future can only be achieved in line with the trends of educational reform and development, Shanghai's urban development in prospect and related industrial development.

According to Shanghai's 13th Five-Year Plan for Urban-Rural Construction and Management [10, 11], the city of Shanghai will make further efforts elevating the level of greenization, elaboration, intellectualization as well as legalization for urban-rural construction and management, improving the systems for integrated urban management and urban-rural infrastructure, and enhancing the city's overall competitiveness. With the speeding up of urbanization, there will be a broad development space for urban construction, management and service oriented to local and surrounding regions and even the whole country. As far as the construction industry is concerned, it still forecasts a steady growth for a considerable term with a bright future. However, it also faces the new trends such as the ever-increasing number of construction projects with great height, grandeur, difficulty and novelty, the higher requirement for design, construction and service quality, and the active emergence of new technologies, techniques and materials, which means there is an urgent need for inter-disciplinary and skilled high-quality talents.

In May 2017, the 11th Congress of CPC Shanghai Committee put forward the vision of Shanghai's urban development--- to build it into "a global city of excellence, a fascinating metropolis of innovation, humanity and ecology". In the future, Shanghai will boast its "buildings for appreciation, streets for strolling, parks for relaxation, honest and civilized citizens who respect laws, and a place always with a touch of warmth" [12]. As SUCC takes urban construction, management and service as its characteristics and orientation, the above-mentioned vision could be both a great opportunity and a major test to the college.

Therefore, SUCC will further analyze the "Three Major Plans" [Shanghai Higher Education Layout Structure and Development Plan (2015-2030)], the Plan for Disciplinary Development and Layout Optimization in Shanghai Universities and Colleges (2014-2020), Shanghai Modern Vocational Education System Construction Plan (2015-2030)] raised by the Comprehensive Reform Plan of Education in Shanghai. Focusing on the new goals and concepts of Shanghai's development and fully studying the demand for talents along the way to enhance the ability and quality of serving the regional economic and social development, SUCC will take the following measures. First, establish and constantly improve on the working mechanism and the management system oriented to connotative development by perfecting the internal governance system. Second, improve the faculty performance by adhering to the quality-promotion path of connotative development, deepening the reform of personnel system and perfecting the incentive mechanism. Third, raise the level of talent cultivation by strengthening program construction and developing new education and teaching mode. Fourth, optimize the resource allocation mechanism by enhancing foreign cooperation and exchange. At present, SUCC is initiating an activity of Great Discussion themed "College Development in Highlight" to design an excellent top-level mid-and-long term blueprint by gaining consensus among all faculty and staff and collecting their wisdom. As an expectation, SUCC will be built into a first-class vocational school featuring closest alignment with the regional and national needs of urban construction, urban management and urban service, playing a greater role in serving the Belt and Road countries.

SUCC will always be regarding the industry-education 
integration and college-enterprise cooperation as the core and key of upgrading school-running level as well as improving the quality of technical and skilled talents [13]. In this respect, the close and stable partnerships with enterprises in related industries are also seen as the lifeline of its program construction. The implementation of college-enterprise cooperation serves various purposes including offering students internship and job opportunities, facilitating the formation of the cultivation mode of technical and skilled talents, improving teaching quality, providing a platform for rendering research and technology service, offering practice and training bases, and supporting the construction of faculty [14]. Enterprises should not only participate in the process of talent cultivation of the college, but also jointly take part in drafting the cultivation program and curriculum standards. SUCC values and actively builds the partnerships with enterprises in related industries, such as Shanghai Construction Group and Shanghai Urban Construction Group, and is making efforts to create a win-win situation for both sides. Together, we set the industrial and professional standards, develop professional positions, design the talent cultivation program and update curriculum, carry out job-oriented training and internship, train faculty members and employees, share technical knowledge, as well as make collaborative innovation. For instance, pilot projects of modern apprenticeship are underway in the programs of Food Quality \& Safety and Hotel Management at SUCC. The experimental mode of "Dual Certificate Integration" (the Academic Certificate and the National Vocational Qualification Certificate) in several majors is being implemented, represented by Landscape Engineering Technology and Construction Project Management (Elevator Orientation). SUCC is also carrying out the order-placing pattern of cultivation, educating interdisciplinary personnel of technology, management and operation who meet the urgent needs of enterprises willing to extend overseas business. Other related activities include the setting-up of assembled building construction bases for production, teaching and research, the developing and training of prefabricated concrete technicians. So far, the mode of industry-education integration and college-enterprise cooperation is strengthened in more majors, as shown by a batch of master studios on campus, and a number of instructional resources database, curriculum, CCAI (Cloud Computing Assisted Instruction) platforms, and production- teaching-research coordination bases commonly developed with many enterprises. It is believed that students' capacities would be better promoted and SUCC's function of serving the industry would be displayed.

\section{4. "Exploring the Rules", Innovating Cultivation Mode of Technical and Skilled Talents}

The requirements from the society and industry enterprises for high-quality technical and skilled talents are increasingly strict, which urges the college to unceasingly explore the rules of cultivating such talents, in order to continuously improve the quality of talents cultivation.

Shanghai Modern Vocational Education System Construction Plan (2015-2030) proposes the general goal -constructing a modern vocational education system which tightly combines market demands with labor employment, developing school education and vocational training simultaneously, integrating vocational education and industry, enabling vertical convergence and lateral communication, embodying the concept of life-long education, having a reasonable structure and diverse functions, covering urban and rural school-age youth and all workers, penetrating through learning and working periods, meeting the diversified and different needs to improve the overpass of talents cultivation. It also puts forward a new work pattern of guiding each major to form a reasonable talents cultivation mode based on the present situation of institutions according to technical and skilled standards and requirements of theoretical knowledge level from the existing industry enterprises. In addition, the plan designs 6cultivation modes-secondary vocational education, vocational college education, applied under-graduate education, vocational consecutive education (5-year joint education, with 3-year secondary vocational education and 2-year higher vocational education), applied undergraduate joint education (secondary vocational education and undergraduate education $3+4$, advanced vocational education and undergraduate education3+2) and social training. There are also 10 promotion channels for the cultivation of skilled and applied talents.

Since 2012, the predecessors of SUCC have carried out the pilot program of "consecutive secondary and higher vocational education", actively exploring the integration of training programs, the design of curriculum modularization and the "secondary-advanced vocational education" joint teaching and research mechanism. Hence, the professional talent cultivation program, like Architectural Engineering Technology, was constructed which raises high requests for both skills and theoretical knowledge, and the mode was positively promoted in the following years. The first cohort of students completed higher vocational studies and graduated in 2016. At present, 14 programs have carried out "joint secondary-higher vocational education" with 10 secondary vocational schools involving Real Estate Management, Engineering Survey Technology, to name a few. In 2017, more than 670 students entered SUCC from various secondary vocational schools through the transition, and the anticipated enrollment from secondary vocational schools exceeded 900 for the joint programs.

Approved by the Shanghai Municipal Education Commission, Shanghai formally implemented the pilot project of "joint higher vocational education - applied undergraduate education" in 2017, which means that a new cultivation mode in the "Vocational Education Plan" has been put into practice. One applied undergraduate university and two advanced vocational education were selected for the first batch of pilot projects. SUCC was fortunate to be selected to be one of the pioneers, with its program "Architectural 
Engineering Technology" bridging with "Civil Engineering" of Shanghai Institute of Technology.

In order to promote the implementation of this new talent cultivation mode, in 2014, Office of Higher Education in Shanghai Municipal Education Committee took the lead, followed by the former three colleges of SUCC. Respectively, they worked with Shanghai Institute of Technology, studying and exploring the implementation of bridging cultivation "higher vocational education-applied undergraduate education". A special team was set up by universities and related advanced vocational education to study and make a scheme for the implementation of the mode.

According to the requirements of the pilot project, the first batch shall concentrate on those majors with higher technical criteria, longer training period and strong and stable social demand. The Implementation Plan stipulates: With undergraduate colleges taking the lead, advanced vocational education and industry enterprises make joint efforts to design a systematic cultivation scheme of professional talents education, including cultivation objectives, cultivation modes, curriculum systems, curriculum standards, teaching plans, assessment requirements, resource allocation and other topics.

According to the production characteristics of the construction industry, in line with the real tasks and career development paths of on-site engineers and project engineers of the construction enterprises, the cultivation scheme of "Architectural Engineering Technology-Civil Engineering" saw breakthroughs. Its curriculum system was reconstructed and teaching contents optimized. The original curriculum systems of higher vocational education and undergraduate courses which were separated and irrelevant were effectively integrated into a more scientific and reasonable system. To be specific, the courses and teaching contents were modified in the way of "pre-posing, post-posing, penetrating, increasing or decreasing", so as to eliminate overlapping and crossing sections. An advanced teaching plan centered on comprehensive quality and professional competence cultivation is formed. For teaching methods, the scheme adopts the combination of learning and working, which emphasizes that "learning" guides "doing" and thus "doing" promotes "learning" [15].

Drafted by Shanghai Institute of Technology, SUCC and Shanghai Construction Group, the Joint Cultivation Plan on the Programs of Architectural Engineering Technology- Civil Engineering in Higher Vocational Education through Undergraduate Education was approved by the Ministry of Education after several rounds of expert demonstration organized by Shanghai Municipal Education Commission. It was formally involved into 2017 National Enrollment Plan, and the first group of students will come to SUCC soon.

SUCC is fully aware that the construction circle, industries and enterprises are in particular need of technical and skilled frontline application-oriented talents equipped with good professional attainments, skills and self-learning abilities under the circumstances of diversified demands for talents in modern construction projects and extensive application of new technologies and materials. These talents shall have compound qualities in designing, building, mastering safety rules and handling emergencies so that they can be qualified for the job even as newcomers. The implementation of "consecutive higher vocational and undergraduate education" pilot can not only better meet the needs of industry and enterprises for talents, but also promote the upgrading of the industry, and help to change the current unreasonable structure of technical and skilled talents team as well as the general shortage of high-quality technical and skilled talents. At the same time, this new cultivation mode has opened a new pathway for the development of technical and skilled talents. In addition, it not only pushes the applied undergraduate universities to thoroughly explore the rules and requirements of the applied talents cultivation, but also promotes the advanced vocational education to deliberate more profoundly about the key issues of educating high-level technical and skilled talents, in order to further deepen the reform of the curriculum system, teaching content and methodologies and enhance the construction performance of programs. In the future, SUCC will continue to seize the opportunity that Shanghai is building itself into an outstanding global city and boosts its "Four Brands" namely Shanghai Service, Shanghai Manufacturing, Shanghai Shopping and Shanghai Culture, strive to form 4-5 characteristic major groups which are closely aligned to the industrial chain and innovation chain.

\section{Conclusion}

The main task facing advanced vocational education at present and in the future is to improve the capabilities of schooling and the quality of talents cultivation by keeping up with the pace to build the modern vocational education system. With a long schooling history, the newly-merged SUCC originates from three advanced vocational education and is standing at a new starting point of development. To realize innovation in inheritance and development in integration, SUCC bears great responsibilities and expectations. An excellent college can be made through multiple efforts. First, we have to actively adapt to the needs of national and regional economic and social development, as well as to the situation and tasks of the comprehensive reform of national and local government in education. Second, we need to grasp and make good use of all kinds of development opportunities, penetrating into the industry and enterprises in all-round way. Third, we must constantly hold up to the core mission of improving the ability of talent cultivation, actively explore the rules and paths for improving the quality of talent cultivation, unceasingly innovate the mode of personnel cultivation. It is in serving the society that SUCC can give full play to its own functions, enhance its own characteristics and the strength of schooling [16].

\section{Declaration}

Please note that this article is a new study based on the author's original research published by China Construction Education, No. 1, pp22-25, 2018. Focusing on promoting the ability in cultivating the technical and skilled talents, the 
recent practices in SUCC are introduced in the current research from the prospects of meeting the needs of the national and regional economic and social development by enhancing the integration between industry and education. The references are newly listed which help explain the well-adapted and trend-following way SUCC has sought for setting up its innovative mode to cultivate high-quality workers and skilled technical personnel.

\section{References}

[1] Comprehensive Reform Plan of Education in Shanghai (2014-2020), http://www.shaeg.com/2017/09/21/211814131701005716.html.

[2] Shanghai Higher Education Layout Structure and Development Plan (2015-2030), http://www.shanghai.gov.cn/nw2/nw2314/nw2319/nw12344/u 26aw45954.html.

[3] Ma Shuchao, Guo Yang, Higher Vocational Education, Striding, Transforming and Improving. Higher Education Press, 2008.

[4] Decision on Accelerating the Development of Modern Vocational Education, http://www.gov.cn/zhengce/content/2014-06/22/content_8901. htm.

[5] Shanghai Modern Vocational Education System Construction Plan (2015-2030), https://www.tech.net.cn/news/show-88135.html.

[6] Action Plan for High-quality Development of Vocational Education in Shanghai (2019-2022), http://www.shanghai.gov.cn/nw2/nw2314/nw2319/nw10800/n w39221/nw44779/u26aw63168.html.
[7] Three-year Plan for Innovation and Development, http://www.shanghai.gov.cn/nw2/nw2314/nw2319/nw12344/u 26aw50115.html.

[8] Ye Yinzhong, Guiding the Reform and Development of Schools with the Spirit of the "Nineteenth National Congress" [I], Shanghai Urban Management, pp10-16, No. 5, 2018.

[9] Ye Yinzhong, Guiding the Reform and Development of Schools with the Spirit of the "Nineteenth National Congress" [II], Shanghai Urban Management, pp4-7, No. 6, 2018.

[10] The 13th Five-Year Plan for Shanghai Urban-Rural Construction and Management, http://www.shanghai.gov.cn/nw2/nw2314/nw2319/nw2404/n w41341/nw41342/u26aw50487.html.

[11] Shanghai's 13th Five-Year Plan for Reform and Development of Education, https://www.lawxp.com/statute/s1777641.html.

[12] Shanghai Master Plan 2017-2035, http://www.shanghai.gov.cn/nw2/nw2314/nw2315/nw4411/u2 1aw1280301.html.

[13] Jiang Dayuan, Colleges and universities should enhance the ability of Deep Participation in the integration of industry and education, China Higher Education, pp23-24, No. 1, 2018.

[14] Ma Shuchao, Guo Wenfu, Experiences, Problems and Countermeasures in Deepening Industry-University Integration of Technical and Vocational Higher Education, China Higher Education Research, pp58-61, No. 4, 2018.

[15] Some Opinions on Deepening the Teaching Reform of Vocational Education and Improving the Quality of Personnel Training in an All-round Way issued by the National Ministry of Education, http://www.moe.gov.cn/srcsite/A07/moe_953/201508/t201508 17_200583.html.

[16] Huang Daren, The future of Higher Vocational Education, The Commercial Press, 2012. 